\title{
AN AGRICULTURAL DEVELOPMENT PLAN CONCERNING THE CIRCUMSTANCES AFFECTING THE PRODUCTION $\left.{ }^{1}\right)$
}

\author{
A. MARIS Documentatie \\ Agricultural Economics Research Institute ${ }^{2}$ )
}

\section{INTRODUCTION}

As late as the end of the 19th century agriculture was still the principal means of living in the Netherlands as it employed about 35 percent of the employed male population. However, since then an important change has come about in the economic structure of our country. In 1947 less than $20 \%$ of all employed persons were employed in agriculture. This development is closely related to the increase in population and the absorption-capacity of the agricultural branch. In the period 1890-1947 the population increased from about 4.5 to 9.7 million, i.e. an increase of $115 \%$; and the total number of employed men increased during this period by $125 \%$; but as employment in agriculture could only be extended to a limited degree - the number of men employed in agriculture increased from 452.000 in 1890 to 589.000 in 1947 - from this period a relative decrease in agricultural employment resulted.

The growth of the population of the Netherlands had to be met by a considerable increase in non-agricultural employment, viz. manufacturing industries, commerce, transport, and supporting business, and therefore a great deal of attention was paid to their development. After the second world-war this interest in industry was reflected in the drawing up of memoranda concerning the industrialisation of the Netherlands; the fourth of which has now been published. In these memoranda the desired expansion of industry is based upon the increased number of persons which have to be placed in industrial trades each year, obviously emigration and other occupations being taken into account. In addition much attention is also being paid to the need for capital investments, to the market conditions and market difficulties and in connection with the trend industrialisation in our country has to take, to the training of labour and the distribution of industries, and to the provision of transport and public utilities; these latter items are specifically dealt with in the more regionally evolved provincial memoranda. From these memoranda amongst others a development plan has resulted, whereby 9 districts in the Netherlands are declared problem (distressed) areas and on which 45 million guilders will be spent for improving the factors favorable for development of industries.

However, this concern in industry, commerce and transport is not to detract the attention from agriculture in which still $1 / 5$ th of the working population is employed. On the contrary, during this same period agriculture claims the utmost attention on account of the many problems that have been created by the increasing industrialisation in the Netherlands. In this connection may be pointed to adequate information on the choice of school and profession necessary for a sufficient and early removal of rural youth to other branches of industry. Consideration must also be given to the regional distribution of industries so that specific rural areas are maintained and the best soil is

1) Received for publication June 1, 1953.

2) Van Stolkweg 29, The Hague. 
utilised for farming. Finally it is necessary to raise the standard of living of the agricultural population, to avoid great differences in the prosperity of rural and urban people.

Considering the many problems in agriculture, which ask for both, economically and socially justified solution, it seems necessary to set up an agricultural development plan in conjunction with the industrial development plan.

\section{BACK-GROUND AND CONTENT OF THE PLAN}

The matter to be discussed in this agricultural development plan and to be called circumstances affecting the production ${ }^{3}$ ) is part of the agricultural policy. Hence it may seem desirable for the present to place these factors affecting the production within the framework of the general agricultural policy. With this in mind three aspects may be distinguished:

1 Market conditions and price levels;

2 Technique of the production;

3 Circumstances affecting the production.

These three aspects determine the material prosperity in agriculture and therefore the income of the farmer and farm-labourer. There is sometimes a danger of overemphasizing the importance of market conditions and price levels and to proclaim a policy based exclusively upon these factors. However, apart from the fact that the market conditions are merely one of the factors which determine the income of the farmer, the most important factor in agricultural, production is the highest possible productivity per worker, coupled, at least under Netherlands' circumstances, with the maximum production per soil unit. This asks for farm management on a high level. For this reason high yielding varieties of crops should be grown or in the case of livestock the most suitable breeds kept. Rational cattle feeding is necessary, as is adequate supply of fertilizers to the soil. For some tens of years past, great attention has been paid in the Netherlands to the more technical aspects of agriculture, apparently with successful results. Research and advice on the technical aspects alone, however, is not sufficient. Management on a high level is only possible when the circumstances affecting the production are favourable, since obviously such a management is closely related to these circumstances, lies so to say embedded in them.

In general it can be stated that agriculture in underdeveloped areas is at too low a level of efficiency because circumstances affecting the production are bad and the productivity per worker is low. If in the Netherlands agricultural conditions in the riverclay soil areas and on the sandy soils are compared with those in Groningen and Zeeland, the question arises why prosperity in the latter areas has always been greater than in the riverclay area and on sandy soils. The most important reason is, in our opinion, the more favourable circumstances under which the production takes place in the seaclay areas.

Having discussed in outline the problems an agricultural development plan has to deal with, the contents of such a plan will now be detailed.

3) Meant is : circumstances which determine the concrete form, in which the production factors canital, labour and land meat in the productionprocess. 
In the first place an insight is to be gained into the character of the most important circumstances which affect the production. In such a way a picture is obtained of the agricultural "climate" under which the farmers have to work. The circumstances affecting the production which any how have to be considered are the following:

1 The size of the holdings;

2 The spatial structure of land use and the accessibility;

3 The control of water levels ;

4 The juridical structure of the land use ;

5 The transport situation and the provision of public utilities;

6 The financing of agriculture;

7 The demand for and the supply of labour in agriculture;

8 The efflux of rural youth and advice on the choice of school and profession;

9 Instruction in agriculture, horticulture and home economics;

10 The rural health and the accomodation of farm homes and buildings;

11 The social activities and the adaptability of the rural population.

Research on these problems can give a sufficiently clear picture of the circumstances under which the agricultural production takes place so that it can be decided which factors are important impediments in raising the production level and which should be the first to be considered for improvement. Memoranda can then be drawn up for areas, provinces and countries; the contents of which can be more or less detailed depending upon the extent of the area considered.

For instance in The Hague with regard to the annual efflux of rural youth out of agriculture and the number of agricultural holdings which are too small, it is sufficient to mention the figures 12.000 and 40.000 . These figures are significant for determining desired emigration and industrialisation and for a possible drawing up of a plan for the consolidation of the size of agricultural holdings. On the contrary in a certain small village it can be stated that holdings similar to that of farmer Johnson are too small and that this son will have to find nonfarm employment.

As examples of the way in which the abovementioned circumstances can be approached quantitatively, we may refer to an article in the Landbouwkundig Tydschrift of October 1949, and an article in the Tydschrift voor Economische en Sociale Geografie of June/July 1952, and two articles in the E.S.B. of December 3 and 10, 1952. These articles deal respectively with: the efflux of farm youth, the consolidation of small farms, and the situation of agricultural instruction in the Netherlands.

It is obvious of course, that by drawing up all these separate memoranda, an agricultural development plan - the ultimate aim - has not been achieved. In order to be able to formulate and discuss an agricultural development plan, the memoranda will have to be integrated into a plan of action in which the measures necessary to improve each area are stated after all factors have been considered in their correct relationship. In this respect it is important to trace by means of some relevant figures the most important problem areas in the Netherlands. 


\section{How IS THE SITUATION IN THE NETHERLANDS?}

Although the Netherlands as a whole can certainly not be considered as to belong to the underdeveloped - or even the less developed-countries, nevertheless from an agricultural viewpoint different areas can be indicated as underdeveloped, for example the riverclay areas, the areas along the former Zuiderzee, various sandy areas and some areas spread across the rest of the Netherlands. These areas therefore deserve every attention. The farmers in these areas will not obtain relief from a certain price level, fixed according to the average production circumstances.

Since the great agricultural crisis at the end of the 19th century the central government undoubtedly has given close attention to agriculture. The government, having pity on the poor state of agriculture then, initiated a system for agricultural research, extension, and instruction. This has now grown into a tremendous organisation, of which the agricultural University, secondary and primary agricultural instruction, a general extension service and the experiment stations and institutes for agricultural research are part. In this system the fundaments were laid for the technical rationalisation of agriculture.

However, it was soon proved that you cannot have one thing without another. It became clear that, however great the results of this technical rationalisation, they were not sufficient. How can work be fruitful if the average number of parcels of one holding amounts to 18, the drainage and accessibility of the land is insufficient or the leasing system leaves much to be desired? Inevitably attention had also to be paid to the ways in which the soil is used, as regards its culture-technical and juridical aspects. With regard to the latter, only the lease act of 1937, its revision in 1941, and the preliminary bill of a new lease act need to be mentioned in order to be able to state that the times when there was talk of the gnawing sore of share-cropping, hereditairy lease and tithe, are now far behind and that the period of private and public leases and annual leases of grass for hay production also belong to the past. The culture-technical rationalisation of our soil has also been undertaken. In the beginning by the Nederlandse Heidemaatschappy, and since 1935 by the Cultuurtechnische Dienst, the governmental service of land improvement. About 62.000 ha are now ready, 70.000 ha in execution, and the reallocation of 360.000 ha has been applied for, whereas at least 700.000 ha of sandy soil need reallocation. Obviously problems of urgency are going to play an important role here.

Experiences gained with this culture-technical rationalisation have proved that any consolidation has a considerable influence upon rural life, economically as well as socially, and the conviction is rapidly gaining ground that this culture-technical consolidation alone does not solve the problems. Certainly it is evident that in many areas the size of the holdings, the supply of labour, skill, mentality, and the sources of credit, are as many impediments which handicap the development of agriculture. Although government intervention in agriculture started in a small way, it has led to an ever increasing interference, from which there can be no escape.

It is of great importance in any consolidation of the circumstances affecting the production that the whole complex is examined. For instance it is senseless to make the culture-technical factors perfect if the people do not know how to use the improved circumstances or if the size of the units cultivated is too small or if the farmers have no capital or are afraid to contract a loan 
in order to adapt their farming methods to the ideal culture-technical factors. It has gradually become well-known that the effect of a reallocation - preeminently a culture-technical consolidation - is greater if the population in the area concerned is more educated and the unit worked per labourer is larger. However, it would be incorrect to draw the conclusion from this that therefore all energy has to be focussed on the further development of the better areas. The conclusion to be inferred should rather be that any endeavour for improvement must be directed towards the less developed areas in the first place, and an amelioration of all circumstances should be attempted rather than a correction of a few of these production circumstances.

Reviewing government intervention in agriculture during the period 18901950 , it appears that not only the extent of this intervention was increased but its character has also changed, in that initially attention was paid chiefly to matters where the individual farmer himself could take action and later on also to subjects which are beyond the power of the individual farmer. The question arises whether these latter subjects are to be considered as belonging entirely to the sphere of government action. Without going further into the matter it can be stated that in this field a close collaboration between the government and the agricultural industry is of prime necessity.

\section{The INTERNATIONAL ASPECT}

In international relation the circumstances affecting the production are of the greatest importance for raising the prosperity level. It is an established fact that in agriculture the differences in productivity per worker and consequently in the prosperity level between different countries are enormous.

It is now customary to call the countries with a low prosperity level "underdeveloped countries". The cause of these great differences in the prosperity level of the agricultural population in the different countries is not so much the fact that the production-plan is different - for this is chiefly determinated by the soil, topography, and climate - but rather the production-technique, because of the greatly divergent conditions under which agriculture is carried on. Obviously in the countries of the Middle and Far East, when taking into consideration the relations between the tenant and the landlord, the deficient credit system, the smallness of the holdings, and the low level of professional knowledge and formal social organization - to mention only a few of the most unfavourable circumstances - a high production level and a prosperous population can hardly be expected. In these countries - and not only in these but also in various European countries - attention will have to be directed first and foremost towards the above-mentioned circumstances, because these are the real bottle necks which stand in the way of raising the agricultural efficiency.

There is little sense for many countries, including some European, in registering the production-technique in detail through accurate observations such as book-keeping, when the factors hindering development are obviously situated elsewhere. Such accurate observations are valuable only if circumstances allow a proper production-technique. It will therefore bring more grist to the mill if in these underdeveloped countries the search-light is focussed in the first place on the circumstances affecting the production and their improvement. By drawing up a number of memoranda for the countries concerned on the most important ones of the above-mentioned circumstances and by comparing 
these countries, a well-considered plan for action on an international level could be achieved to improve these circumstances and by doing so, to obtain after some time a production-technique which may give a reasonable level of prosperity to the population. In accordance with the various levels of development of the countries involved, the plan could cover a few years to a period of even five or ten years.

However, the research and such measures as to appear necessary need not wait until an integration of agriculture has been accomplished.

It could even be suggested that an improvement of the circumstances affecting the production would benefit the agricultural integration. For the ultimate aim of integration is to increase the prosperity of the participating countries and, if possible, of all trade groups - eventually coupled with possible quantitative changes within these groups - in these countries. An attempt to achieve this is made through a better spreading of labour and a more justified investment of capital, whereas working in a wider sphere and in ampler relations may itself also stimulate productivity. In some countries the consequences for the agricultural industry could be :

a decrease of the total number of persons employed in agriculture, a decrease of the area under cultivation and exploitation, enlargement of the holdings and the extensity of their management. These are structural alterations that we consider of such importance that they may explain the small inclination of some countries to start integration at short notice.

It is easily understood that these alterations would not be enacted at a rapid pace but could only come into being in a gradual process of adjustment. The significance of an improvement of the circumstances affecting the production in this connection is twofold: in the first place adjustment would be made easier and in the second place the adjustment would have to go less far ; in both cases the result would be a greater inclination to proceed to integration.

But whatever one thinks of integration, it is clear in our opinion that a co-ordinated start of the above-mentioned activities can be made at once and could even have been started immediately after the war. As a matter of course, the situation is that in various countries an improvement of certain circumstances has already been worked on for a some time, but it is also true that in other countries little activity is noticeable and for practically all countries it is true that a systematically co-ordinated start has not yet been made to achieve a general improvement - dependent on the position of agriculture in the countries; more or less perfected - of the circumstances affecting the production. There is no escaping from the impression that in general much more attention is paid to price relations and manipulations at the border than to an improvement of the agricultural "climate".

\section{SUMMARY}

Summarizing, the conclusion can be, that schematically spoken three aspects can be distinguished in a general agricultural management, viz.: the market- and price-political aspect, the aspect of the production-technique, and in the third place the aspect of the circumstances affecting the production.

An agricultural development plan aims at giving a survey of a co-ordinated start for the improvement of the circumstances affecting the production. This 
plan of activity is to be based on a number of memoranda on these circumstances which can be drawn up at fairly short notice. These memoranda may be drawn up for areas, provinces, and countries and, depending upon this, the amount of detail can be changed. In order to achieve the aim in view it is essential that not only one circumstance be improved, but that all are consolidated in harmony. In order to raise prosperity in an area, c.q. establish it solidly and maintain it in the future, it is of great importance that the land is properly allocated and accessible and that the units are of adequate size and farmed by well trained and socially minded workers, the supply of which should meet the demand. In addition if farm equipment and the provision of credit are in order, then eventually a proper production-technique is possible and ultimately a reasonable income can be expected for persons employed in agriculture. It is obvious that in the Netherlands for these activities attention is to be concentrated upon the less prosperous areas and in international relation upon the underdeveloped countries.

It will be clear that the individual farmer cannot improve the abovementioned circumstances. The individual farmer may be able to apply one more sack of artificial fertilizer, to plant a higher yielding variety, or to purchase a better plough, but as an individual he cannot correct the allocation of land, enlarge his farm, regulate the facilities for the provision of credit, level up vocational education, or regarding the necessity of an early and adequate efflux of young farmers to other branches of industry, improve information in the matter of choosing a school and a vocation or profession. It is in these fields that a strenuous combined effort is demanded from government and industries. 